\title{
Examination of Technologies and Physical Effects for the Enrichment of Arable Land and Plants Growing on them
}

\author{
Shegelman I. R., Ershova N. Y., Vasilev A. S., Shtykov A. S., Shchukin P. O.
}

\begin{abstract}
In order to address food security problems in Russia, insufficient attention is paid to the development and implementation of innovative technologies for the enrichment of agricultural lands and plants growing on them. Such technologies make it possible to purposefully bring the necessary micro and macro elements to agricultural plants, while ensuring, in turn, a significant increase in the consumer quality of agricultural products. The article discusses innovative technologies for the enrichment of agricultural land and plants growing on them, the use of which will increase the consumption of agricultural food raw materials from each hectare of arable land, as well as the quality of functional food products produced from it. This will increase the competitiveness of fortified products in the domestic and foreign markets and make an important contribution to improving the food security of the country.

The analysis showed that one of the important directions of innovative developments and patents in the field of enrichment of agricultural lands and plants growing on them is the solution to the problem of providing the population of Russia and the world with regulatory requirements for micro and macro elements: iodine, selenium, magnesium, calcium, manganese, zinc, etc., as well as in vitamins by pre-sowing, root, and foliar enrichment of cereal, fruit-bearing and vegetable crops in open and in closed ground. All this, in turn, will help to provide the country's population with high-quality food products derived from enriched agricultural raw materials and increase its competitiveness in the domestic and foreign markets.
\end{abstract}

Keywords : food security, food, agricultural sector, North of Russia, technology, arable land enrichment.

Revised Manuscript Received on October 15, 2019.

* Correspondence Author

Shegelman I. R., Doctor of Technical Sciences, Professor, Cross-cutting technology and economic security, Petrozavodsk State University (PSU), 33, Lenina pr., 185910, Petrozavodsk, Republic of Karelia, Russia

Ershova N. Y., Candidate of Technical Sciences, Associate Professor, Department of Information Measuring Systems and Physical Electronics, Petrozavodsk State University (PSU), 33, Lenina pr., 185910, Petrozavodsk, Republic of Karelia, Russia

Vasilev A. S., Candidate of Technical Sciences, Associate Professor, Technologies and organizations of the forest complex, Petrozavodsk State University (PSU), 33, Lenina pr., 185910, Petrozavodsk, Republic of Karelia Russia

Shtykov A. S., Department of Innovation and Production Activities Deputy Head of Department, Petrozavodsk State University (PSU), 33, Lenina pr., 185910, Petrozavodsk, Republic of Karelia, Russia

Shchukin P. O., Candidate of Technical Sciences, Senior Researcher, Cross-cutting technology and economic security, Petrozavodsk State University (PSU), 33, Lenina pr., 185910, Petrozavodsk, Republic of Karelia, Russia.

\section{INTRODUCTION}

The most important factors ensuring food security of the countries of the world and their regions are the level of organization of the use of agricultural land, the yield and quality of agricultural raw materials obtained from this, as well as the quality of food products made from this raw material. Theoretical and practical aspects of the problems of efficient use of agricultural land in the world, Russia, its regions and specific enterprises are considered in the works presented by V.B. Azarov, L.N. Alexandrova, A.I. Altukhov, N.B. Bakirov, S.A. Bartalev and E.A. Lupyan, E.A. Bessonova, V.G. Bryzhgo, I.N. Buzdalov, A.A. Varlamov, S.N. Volkov, A.P. Vorontsov and N.Z. Kharitonova, L.M Derzhavin, D.S. Bulgakov, V.V. Dokuchaev, N.Ya Kovalenko, V.V. Kowalski, Z.A. Mashinina, T.I. Nasedkina, A.I. Perelman and N.S. Kasimov, G.A. Ponomareva, V.V., Plotnikov, L.I. Prasolov, A.A. Rode, B.G. Rozanov, V.N Savich, N.V. Parakhin, V.G. Sychev, V.A. Tyapkin, V.Ya. Uzun and many other scientists.

The analysis showed that special attention is currently being paid to the development of research in the field (Shegelman, Vasiliev \& Shchukin, 2018; Shegelman, Shchukin \& Vasilev, 2019).

- studying the features of territories - sources of agricultural food raw materials for the implementation of end-to-end technologies for the production of functional food products, since under different geochemical conditions the chemical composition and metabolism of plants and animals, even representatives of the same species, can vary significantly;

- the formation of end-to-end technologies for the procurement, transportation of food raw materials and the production of functional food products from it as a factor in increasing regional food security.

At the same time, the analysis showed that in Russia insufficient attention is paid to the development and implementation of innovative technologies for the enrichment of agricultural lands and plants growing on them.

This happens despite the fact that research by domestic and foreign scientists testifies to the merits of such technologies, which make it possible to purposefully bring the necessary micro and macro elements to agricultural plants, while ensuring, in turn, a significant increase in the consumer

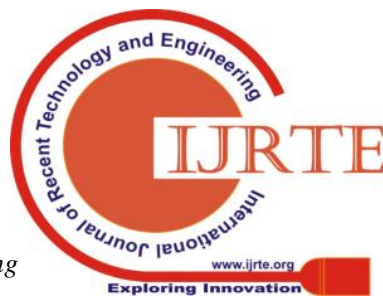


quality of agricultural products (Lubimaya, 2014).

The need to implement this approach to the development and implementation of innovative technologies for the enrichment of agricultural land and plants growing on them will allow not only to increase the removal of agricultural food raw materials from each hectare of arable land, but also to improve the quality of functional food products produced from it, increasing their competitiveness in domestic and overseas markets and making an important contribution to improving the country's food security.

All of the above led to the following analysis of methods to improve the use of arable land for the production of agricultural food raw materials by enriching both these lands and agricultural plants growing on them.

\section{LITERATURE REVIEW}

As noted by Amagova Z.A. and Golubkina N.A., increasing the resistance of plants to adverse environmental factors is fundamental in obtaining sustainable crops and high quality agricultural products. Abnormally low and high temperatures, waterlogging and drought, bacterial infections and exposure to harmful insects are significant risk factors when growing various crops. In recent years, much attention has been paid to the possibility of protecting plants from various forms of oxidative stress by enriching plants with the trace element selenium, which is a natural antioxidant. Under conditions of abnormally low temperatures and high humidity, the influence of foliar enrichment of tomato selenium (Solánum lycopérsicum) on the yield and biochemical parameters of fruits was studied. Studies have shown that the dose $4 \mathrm{mg} \mathrm{Se} / \mathrm{m} 2$ in the case of triple foliar treatment during the growing season significantly increases the content of vitamin $\mathrm{C}$, sugars, titratable acidity, beta-carotene, lycopene. At a 16-fold level of micronutrient enrichment, fruits are a good source of selenium, providing $22-29 \%$ of the adequate level of selenium intake in the human body (per $300 \mathrm{~g}$ of fruits) (Amagova, 2018).

Experts emphasize that thanks to the technology of enrichment of arable land with mineral fertilizers, a qualitative increase in the content of mobile forms of nitrogen, phosphorus and potassium in the arable layer of the soil is provided, this in turn creates the necessary conditions for increasing the natural productivity of agricultural soils and allows you to increase the yield of grain and legumes cultures (Azarov, 2004).

As it known, agricultural plants can be enriched by applying solutions of different salts to the soil, both in conjunction with mineral fertilizers, and by spraying (watering) with solutions of these salts of agricultural plants (Hong Chun-Lai, Weng Huan-Xin, Qin Ya-Chao, Yan Ai-Lan \& Xie Ling-Li, 2008). Therefore, in the field of crop production, preparations are being actively developed for root and foliar top dressing of cereals, fruit-bearing crops, vegetables in open and closed soils, as well as indoor, ornamental and other plants. Particular attention is paid to iodine (I) and selenium (Se), which are included in the group of elements important for the nutrition of the population: Fe, $\mathrm{Ca}, \mathrm{Mg}, \mathrm{I}, \mathrm{Se}, \mathrm{Zn}, \mathrm{Cu}$. As you know, domestic and foreign scientists note a significant need to solve the problem of eliminating the deficit in these elements among various population groups of different countries of our planet (White \& Broadley, 2009).

Numerous publications are devoted to technologies for enriching and improving soil fertility, improving soil structure and enriching humus with green manure, when the green mass of specially grown green manure plants is smelled into the soil, such as works written by Begeulov M.Sh.and Loshakov V.G. (2015), Gaplaev M.Sh. and Tsabolov P.H. (2011), D’yachenko E.N., Razina A.A., Shevelev A.T. and Dyatlova O.G. (2018), Khalmanov N.T. (2017).

In the monograph written by Kashin V.K. (1987), the possibility of using iodine as a highly effective microfertilizer with its lack in the external environment for enriching food and feed with this element and as a universal biogeochemical indicator in the search for deep-seated minerals is studied. The work of the Institute of General and Experimental Biology Siberian Branch of the Russian Academy of Sciences (Kashin, 2008) also showed the possibility of enriching plants with iodine by introducing iodine micronutrient fertilizers.

The work of the North Caucasus Federal Scientific Center for Horticulture, Viticulture, and Winemaking (Vorob'eva, 2018) showed that a slowdown in the process of soil degradation in vineyards can be provided by biomaterial in the form of humified plant substances that act as suppressors of phytopathogens and destructors of persistent organochlorine preparations. Winemaking waste was used as biomaterial in combination with effective microorganisms (Baikal EM-1 preparation) and potassium humate preparation. This made it possible to improve the physical and mechanical properties of the soil and to activate the detoxification process of persistent organochlorine substances. As shown in research conducted by Krasilnikov A.A., Russo D.E. and Prah A.V. (2018), the use of special complex fertilizers of the "AgroMaster" group of companies with annual spraying (seven rounds of spraying annually at a flow rate of 2000 liters per hectare) can improve plant productivity and the quality of their processing.

As shown in the work of scientists of the Agrochemical Testing Center of the All-Russian Institute for Vegetable Breeding and Seed Production (Golubkina, Kekina \& Nadezhkin, 2015; Alwahdani, 2019), both of the above elements are powerful and effective immunomodulators, natural antioxidants, the use of which in the required amounts will contribute to the effective protection of the body people from the effects of various kinds of stress. Attention to the use of these elements for enrichment at various stages of the production of agricultural food raw materials and related food products is caused by their urgent need for the growth of children and adolescents, to ensure the normal functioning of the brain activity of people, as well as for the reproductive system of the body. According to many experts, to date, there remains an urgent need for the population of various countries in the world to eliminate polymicroelementoses and this, in turn, makes research and identifying effective ways for both separate and joint biofortification of agricultural food raw materials using iodine and selenium a priority. Such a methodology, when implemented, can provide an inexpensive and

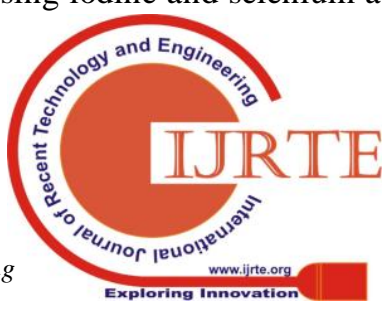


highly effective way to improve iodine and selenostatus to improve the health of the population of different countries of the world.

An important problem is the need to provide the population of Russia with regulatory requirements for iodine. According to Melnichenko, Troshin, Platonov, Savchuk and Yakunchikov, in Russia the average consumption of iodine by residents is three times less than the established norm, which causes a serious threat to the health of 100 million Russians, while maintaining the threat of impairing the physical and mental development of 32.8 million children living in Russia. The authors concluded that in order to prevent the spread of iodine deficiency and a corresponding reduction in the risk of the development of its consequences, systemic prevention and improving the literacy of the population on this issue is necessary (Melnichenko, Troshina, Platonova, Savchuk \& Yakunchikova, 2016).

As shown in the study (Karataeva, Selivanova, Chervyakovsky, 2015), in our time, spinach, lettuce, cabbage and tomatoes are the most popular cultures for studying the processes of ensuring normal iodine content in plants and for fighting iodine deficiency, iodide or potassium iodate, organic fertilizers based on seaweed, an iodine-containing substrate are introduced into the soil before sowing, as root top dressing, sprayed onto the aerial part of plants, or the last two methods are combined. The authors of this work were enriched with iodine using an iodine-containing drug of their own production based on potassium iodide (working title UNIFORT). An aqueous solution of the drug was sprayed onto the leaf part of the plants 10-14 days before harvesting and for potatoes 10-14 days before desiccation. The amount of iodine introduced was $2.4-10 \mathrm{~kg} / \mathrm{ha}$, depending on the culture. For potatoes and root crops a single treatment is sufficient; pumpkin and zucchini need a second. Too early a first treatment - before flowering and fruit planting begin does not lead to the accumulation of iodine. Satisfactory results for zucchini (F1 Aral hybrid) were obtained by adding $2.4 \mathrm{~kg}$ of iodine per ha in two equal doses - on the 63rd and 79th days from the time of planting. Applying this method, the amount of iodine in marketable zucchini remains stably high - 39-62 $\mu \mathrm{g} / 100 \mathrm{~g}$ of wet weight during the entire fruiting period. An analysis of the yield of potatoes and carrots showed an increase in yield when using the drug UNIFORT. For the selected varieties of carrots, the increase was $14-28 \%$, for potatoes $-7-46 \%$, for beets $-61 \%$, for pumpkins a slight decrease in yield was observed.

A number of studies substantiate the feasibility of solving the problem of enrichment of food products using selenium as trace elements (Ermakov \& Kovalskiy, 1974; Azim \& Ghodrati Amiri 2016).

Scientists at the Agrochemical Testing Center of the All-Russian Research Institute for Selection and Seed Production of Vegetable Crops expressed the opinion that cereals, which occupy a significant place in the diet of animals and humans, are the most promising crops from crops. Scientists in the southern forest-steppe of the Omsk region studied the influence of the integrated effect of enrichment with selenium and iodine on productivity, the chemical composition and quality of spring soft wheat (Triticum) grains. It has been established that the combined use of selenium and iodine-containing fertilizers at a dose of
$12 \mathrm{~kg} / \mathrm{ha}$ stimulates the growth and development of spring soft wheat and contributes to an increase in grain yield. Due to the phenomena of synergism between these elements in the grain and wheat straw, both the iodine and selenium content increase in comparison with the separate use of these elements. Joint enrichment with these microelements contributes to a change in the chemical composition of spring soft wheat grain (Sindireva, Fedosova, Knyazev, 2017).

Studies (Golovatyi, Kovalevich \& Lukashenko, 2013) performed on sod-podzolic loamy and sandy loam soils showed the effectiveness of selenium fertilizers in the cultivation of perennial grasses.

In the work (Golubkina, Folmanis, Tananaev et al. 2017) spinach enrichment with nanoparticles of selenium and ionic forms of the trace element is estimated using spinach as an example. It was shown that, in terms of the level of enrichment of plants with selenium, nanoparticles occupy an intermediate position between selenite and selenate. Compared to the ionic forms of selenium, nanoparticles maximally reduce the $\mathrm{Cd}$ level in female spinach plants. The research results suggest the possibility of the participation of phytohormones in the accumulation of selenium nanoparticles and a change in the biochemical parameters of spinach plants as a result of biofortification.

The work (Endovitskiy, Esipenko \& Hurum, 2012). examined the germination of seedlings of vanadium-enriched rice seeds. The paper written by Bardak N.I. and Petrik Ya.B. (2017) describes the effect of seed enrichment with copper on rice productivity. Specialists of the Kuban State Agrarian University (Yakovleva, Bondareva \& Sheujen, 2015) studied the effect of iodine and boron fertilizers on the yield and quality of rice grain. It has been established that the use of bacterial biological products (azotobacterin, phosphobacterin, silnebacterin) increases the yield of potato tubers from 1.2-2.5 times, enriches the soil with basic nutrients in a form accessible to plants, inhibits the development of pathogenic microflora, reduces the content of nitrates and nitrites in the crop, accelerates the maturation of potato tubers (Sokolova et al. 2008).

At the present day, it is known that in various countries a methodology has been developed and introduced in industry for the production of various products, including selenium-rich garlic (Állium satívum) in the United States, tomatoes (Solánum lycopérsicum) in the UK and tea (Caméllia sinénsis) and tea in China. It is also known that, since 1985, NPK fertilizers enriched with sodium selenate have been widely used in Finland on a large scale.

As shown in the work (Blinnikova, 2017), about $80 \%$ of the population of different countries of the world receives less magnesium, which negatively affects the functions of the central nervous system, heart and blood vessels, adrenal glands, thyroid and pancreas, and other organs. Emphasis is placed on the fact that magnesium deficiency is characteristic of the diet of the elderly and low-income people. The paper proves the possibility of magnesium enrichment of berries of various crops (honeysuckle, strawberries, colomict actinidia) by foliar treatment of plants with an aqueous solution of magnesium sulfate with the addition of hydrated lime during the formation of berries.

Interesting considered in the work of Weng Y.X., Hong C. 
L., Xia T.H., Bao L.T., Liu H.P. and Ki D.W. technology for enriching plants with iodine using seaweed containing the organic form of a microelement as fertilizers (Weng et al. 2013). We believe that this direction should be considered for implementation in the conditions of coastal marine territories of the North of Russia.

This review demonstrates the urgency of the problem of producing high-quality and competitive agricultural food raw materials by enriching agricultural lands and plants growing on them.

\section{MATERIALS AND METHODS}

The aim of the study was to create a knowledge base based on an analysis of technologies and the application of physical effects to enrich arable land and plants growing on them as an important factor in the production of agricultural food raw materials for food production, including the production of functional food products. The authors proceeded from the position that the generated knowledge bases can be used to analyze the status and development trends of technologies and equipment in the field of enrichment of agricultural lands and plants growing on them, as well as for the synthesis of new patentable solutions.

At the same time, it was necessary to prove that the development of innovative technologies for the enrichment of arable land and plants growing on them creates the necessary conditions for increasing the natural productivity of agricultural soils and increasing the yield of grain and leguminous crops.

The research methodology provided for the collection, generalization and analysis of information collected on the basis of the study of patents, scientific and technical literature with the identification of the features of various arable land enrichment technologies and the physical effects used.

The materials used in this work included the results of systemic patent information searches in a scope of grant "Research and development of end-to-end technology of functional food manufacture for achieving food supply security for north territories of the Russia".

At the same time, there were tasks to identify important areas of innovative developments and patents in the field of enrichment of agricultural land and plants growing on them as the most important factor in solving the problem of providing the population of Russia and the world with regulatory requirements for micro and macro elements: iodine, selenium, magnesium, calcium, manganese, zinc and etc., as well as in vitamins by pre-sowing, root, and foliar enrichment of cereal, fruit-bearing and vegetable crops in open and in closed ground.

The authors proceeded from the hypothesis that the solution of this problem will help to provide the population of the country and the world with high-quality food products derived from enriched agricultural raw materials and increase its competitiveness of the Russian agro-industrial complex in the domestic and foreign markets.

During the research, the task was to identify Russian universities and scientific organizations most actively patenting their developments in the field of synthesis of innovative technologies and the use of physical effects to solve the problem of enriching arable land and plants growing on them to increase the productivity of agricultural soils, increase their productivity, and obtain high-quality agricultural raw materials for human nutrition and animal feeding and on this basis obtain information on the works of leading scientists these universities and organizations on the subject of this work.

In order to achieve this goal, a comprehensive patent information search of literature and regulatory documents in the field of food security was carried out. Particular attention is paid to identifying patented technical and technological solutions. These materials were the basis for the formation of the knowledge base used for the synthesis of new intellectual property in various fields of science and technology.

It was taken into account that agricultural soils and agricultural food raw materials growing on them can be enriched both by applying to the soil and by spraying (irrigating) crops of plants. Therefore, the methodology provided for the search and patenting of new innovative solutions for both pre-sowing, root and extra-root enrichment cereal, fruit-bearing and vegetable crops in open and in closed ground, as well as for pre-sowing enrichment of seeds and tubers.

\section{RESULTS AND DISCUSSION}

Russian scientists are actively working to improve the structure and water-air balance of soils, increasing the fertility of mainly humus-poor lands in arid conditions. For example, the Volgograd State Agrarian University has proposed an original fertilizer, ameliorant, which can improve the water-physical properties and structure of the soil, increase its biological activity and fertility (Pyndak et al. 10.27.2016).

Scientists at the Volgograd State Agrarian University have also proposed the technology of cultivating vegetables and melons. The technology includes controlling the process of placing seeds in a mixture of soil and fertilizers, with the use of self-decomposing pots in agricultural soil made of clay minerals with sorption and ion exchange properties, seed germination and planting the pot in the soil. For the manufacture of self-decomposing pots in the soil, it is recommended to use predominantly natural local clay minerals with sorption and ion exchange properties. For example, for growing vegetables and melons in the conditions of the Lower Volga region, Khvalyn clays are recommended, which occur in about $40 \%$ of the territory of this region (Pyndak et al. 10.27.2014).

According to Italian scientists (Tsanirato, 02.27.2013), 225 million people in the world suffer from violations due to iodine deficiency. Iodine in foods is mainly in the form of inorganic iodide, which is quickly and completely absorbed in the stomach and upper part of the small intestine. The iodine present in food in the form of iodate is quickly restored in the intestine, and the resulting iodide is instantly absorbed. In the aforementioned work it is shown, for example, that a pronounced lack of iodine in consumed potatoes. An analysis of potatoes grown in Italy (Solánum tuberósum) showed that its iodine content is less than $1 \mu \mathrm{g}$ per $100 \mathrm{~g}$. In this regard, the work cited suggests several options for enriching potatoes with iodine and potato compositions obtained according to these options, according to which, through 
agronomic receptions potatoes are enriched with iodine, by applying to the plants a composition of a solution of a compound of iodine, phosphorus pentoxide and potassium oxide. An object of the present invention is to propose a method and composition for enriching potatoes and other vegetables with iodine and to propose iodine-enriched potatoes to obtain functional foods necessary for health and nutrition prevention. Another objective is to propose a method and composition for enriching potatoes with iodine to obtain potatoes with increased iodine content even after cooking and storage, and with unchanged organoleptic properties. Another objective is to propose a method and composition for enriching potatoes with iodine using traditional agronomic techniques using the natural pathways of potato plant metabolism. Potatoes so enriched have an iodine content of at least 25 micrograms per 100 grams of potato. The result is the enrichment of potatoes or other plant foods with iodine, and even after cooking the potatoes and after storing the potatoes, while giving them the organoleptic properties.

To protect plants from diseases and regulate their growth, protective-stimulating complexes (multimineral compositions), saturated with an integrated combination of micro and macro elements, are being developed. For example, the protective-stimulating complex according to the patented invention (Klimenko, 27.12. 2001) includes ammophos, urea, ammonia or sodium carbonate, copper sulfate and water, manganese, boron, molybdenum, sulfur, potassium, magnesium, iron, cobalt . Another multimineral composition for root dressing of plants includes both water-soluble nitrogen-containing components and a wide range of micro and macro elements: copper, iron, boron, phosphorus, manganese, zinc, molybdenum, potassium, sulfur, cobalt, magnesium, calcium, sodium, iodine , selenium, titanium, nickel, aluminum.

As convincingly proved by Russian scientists, the need to enrich agricultural food raw materials and food products is due to the fact that for normal life and effective functioning, a person should regularly consume 50-200 micrograms of selenium per day while eating various foods (Avtsin et al. 1991).

According to (Zubenko et al. 1989; Minakova, 2011), the intake of nutrient compounds, especially trace elements (copper, boron, manganese, zinc, molybdenum, etc.) during the growing season of plants positively affects the growth and development of sugar beet root crops. At the same time, microelements contribute to the normal course of physiological and biochemical processes, improve metabolism in plants, eliminate its functional impairments, and affect the process of chlorophyll synthesis and photosynthesis intensity. Trace elements increase the immunity of plants and their resistance to diseases, acts on oxidation-reduction processes as activators or inhibitors, and thereby positively affect the yield and quality of plant products.

Foliar top dressing with chelated micronutrient fertilizers is one of the main elements of modern technology for growing sugar beets. Studies (Putilina at ol, 2019) showed the high efficiency of foliar dressings with chelated forms of trace elements, characterized by a prolonged action on plant tissues. When applying micronutrient fertilizers
"Polychelates-Svekla" and "Polychelates-BorActive" (NPP ZIPo - TM "MinSemLab") in doses of 1 1/ha as extra root top dressing on the main fertilizer backgrounds N45P45K45 and ${ }^{\wedge} \mathrm{oRdoKdo}$ in sugar beet crops increase in technological indicators of root crops as a result of synergism: sugar content - by 1.36 and 0.79 abs. \%; predicted sugar yield - at 1.28 and 0.60 abs. $\%$ relative to the control option without fertilizers.

This research (Aliyev et al. 2019) showed that the use of mulch materials (cut grass, bark, sawdust) in the near-trunk strip of weak-growing apple trees provided optimal conditions for the growth and development of the roots of weak-growing apple trees, and improved the water regime of the soil and effectively suppressed weedy vegetation, which allowed to increase the yield by an average of $19.1-35.5 \%$, and the average weight of the fetus by $6.7-17.2 \%$, compared with herbicide steam, as well as potential keeping quality and a set of consumer qualities thanks to the content of antioxidants (ascorbic acid, phenolic compounds) in the fruit.

The Volga region research institute for the production and processing of meat and dairy products patented an invention (Gorlov at ol, 09/28/2012) for the enrichment of leguminous seeds with iodine and selenium. The method includes the traditional soaking and germination of legume seeds. Its principal novelty is as follows: chickpea seeds are used as the initial seeds in this method, and a solution of inorganic iodine and selenium salts containing sodium selenite and potassium iodide is used to enrich the seeds. It is also proposed that germination be conducted at a temperature of $20-25^{\circ} \mathrm{C}$ until the seedlings reach a length of $4-5 \mathrm{~mm}$. The authors proved the synergistic effect of the use of sodium selenite and potassium iodide salts, and thanks to this, a significant effect was achieved, since the iodine content in the seeds increased by $93.15 \%$, and the selenium content - by $29.19 \%$.

The All-Russian Research Institute of Physical Culture and Sports and the All-Russian Research Institute for Selection and Seed Production of Vegetable Crops have patented an invention on a method for enriching garlic and root crops with selenium by soaking bulbs and root crops in a solution of selenium salt. The authors showed that thanks to the proposed method, an increase in the accumulation of selenium by garlic (Állium satívum) is 3.6 times, stachis (Stachys affinis) is 3.0 times, Jerusalem artichoke (Heliánthus tuberósus) is 2.6 times, and the icon (Smallanthus sonchifolius ) - 2.2 times.

Tomsk State University has proposed technology for the enrichment of vegetables and cereals with selenium. The technology consists in the systematic processing of plant roots (Golovatskaya et al. 05.27.2012). Selenium salts are introduced under the root of the plant in the phase of the onset of flowering and plants are grown, followed by abundant watering with water.

SB RAS and the Geological Institute of SB RAS patented an invention for a method for producing a prolonged complex selenium-zeolite mineral fertilizer, including mixing mineral micronutrient fertilizer with crushed clinoptilolite-containing tuff, a microelement of selenium is introduced into its matrix, 
impregnating tuff in sodium selenite solution under regulated parameters and this method (Revensky et al. 09/20/2006).

The Kemerovo Technological Institute of the Food Industry has proposed a technology for increasing the content of selenium in medicinal sweet clover (Melilótus officinális) - a natural selenium concentrator by treating a growing clover with an aqueous solution of selenium, which contributes to the subsequent absorption of selenium by the animal organism (Revensky et al. 10.12.2008).

The Ural State University of Economics has patented an invention on a method for enriching amaranth seeds with selenium (Tikhonov et al. 07.16.2019). The method includes soaking and germinating seeds in an aqueous solution of sodium selenite at a temperature of $20-22^{\circ} \mathrm{C}$. Amaranth is used as the initial seed, and the concentration of sodium selenite in an aqueous solution is 0.04-0.06 g/l. Amaranth seeds are germinated for two days with red light irradiation with a wavelength of 640-720 $\mathrm{nm}$ and a light flux area of 35 $\mu \mathrm{W} / \mathrm{cm} 2$ for $6-8$ hours a day until the seedlings reach a length of 3.8-4.2 mm.

The technology of presowing treatment of seeds of agricultural crops is proposed. The technology includes processing the seed - moistening the seeds with a $10-12 \%$ solution of the natural mineral bischofite, increasing the productivity of crops both on various types of soils and in protected ground (Koroleva \& Belitskaya, 12.20.2000).

The All-Russian Scientific Research Institute of Irrigated Agriculture has patented a method (Melikhov et al. 2004.11.2000) according to which seeds are exposed to a liquid medium for 2-8 hours, containing a seed germination stimulator - a brine of the natural mineral bischofite of the formula $\mathrm{MgCl} 2 \cdot 6 \mathrm{H} 2 \mathrm{O}$ at a temperature of $30-45^{\circ} \mathrm{C}$. The treated seeds are exposed to a magnetic field. The concentration of brine is 15-100 wt\% Mineral bischofite.

According to the invention (Nesmeyanov et al. 03.20.2010), it is proposed to use crushed stone made from granite and flint as a natural catalyst, and it is proposed to implement the method by providing plant root systems with biologically active water.

In the scientific literature, it is noted that on podzolic sandy loam soils of the central Non-Black Earth Territory there are not enough volumes of moisture consumed for optimal soil moisture compared to the volume consumed during traditional irrigation, and it is also necessary to protect plants and water-soluble fertilizers from leaching from the soil. And for this we need preparations that are compact, small in size, for example, sorbent granules, which would be able to increase the volume of the granules themselves by abundant watering to accumulate water in themselves, forming the ice structure, or otherwise "hard water". To solve this problem according to the invention (Golubenko, 06/04/2019), a method of enriching the soil with water using superabsorbent and using drainage livestock stocks on sod-podzolic soils of the central Non-Black Soil region provides a drainage network that flows into waste drainage channels artificially created along the boundaries of the fields that have a bias towards an open, closed collector of drainage water collection with a mobile pumping station into a storage pond of drainage water for irrigated livestock waste water with drainage -drab fields. It is filled in the autumn period after the end of irrigation of the drainage and humidification fields with the possibility of precipitated particles falling out of the drainage water in the winter period of its filling in the first year, sedimentation and supply of drainage water in the second year using a closed distribution pipe for irrigation with pumps for sprinkling equipment, and plowing on a dry field. Organic solid fertilizers with granules of superabsorbent are introduced simultaneously on it, carried out in one pass by the unit. Each strip of organic fertilizers is covered with pine and an equally wide strip of granules of superabsorbent. Then they fill up the soil with disk harrows into the soil layer $12-20 \mathrm{~cm}$, and then they smell organic solid fertilizers with superabsorbent granules, which act as a water aggregator, capable of absorbing the liquid, followed by irrigation of the drainage water using the irrigation technique mentioned drainage water from the pond drive. In this case, watering the field on which organic fertilizers are applied and the superabsorbent granules is carried out with a decrease in soil moisture in the active soil layer of the dry field to the lower optimum moisture level, while the superabsorbent granules begin to accumulate the maximum of their ability that does not destroy the soil structure. The supply of drainage water is carried out with an allowable sprinkling rate and a duration that ensures the gradual absorption of drainage water and at the same time water is taken by superabsorbent granules in the soil without disturbing its structure and impairing the quality of irrigation. When plowing on a dry field, on which organic fertilizers with granules of superabsorbent are applied, the composition of the mixture of grass stand naturally growing in this field with a given seeding rate is formed. The technical result of this invention is the expansion of the technological capabilities of safe low-cost and environmentally friendly use of drainage water from animal husbandry with an increase in the activity of soil microorganisms, a decrease in soil density and an increase in the humus content of the soil.

Active BioTech LLC (BY) proposed an interesting composition for plant nutrition, including water-soluble components containing nitrogen, micro and macro elements: molybdenum, boron, sulfur, titanium, nickel, aluminum, iodine, selenium, and water, while it contains yeast autolysate (Khodasevich et al. 04/10/2015). All components are taken in a certain ratio. This allows you to increase the effectiveness of the composition for feeding plants, providing an increase in the growth rate, development, plant productivity and product quality. A similar composition for plants is prepared as follows. An aqueous solution of yeast autolysate is preliminarily prepared, into which, after holding for 40-60 minutes, aqueous solutions of micro- and macroelement components are introduced with constant stirring. For use, the resulting solution is diluted with water, depending on the types of crops and the period of development of plants in a ratio of 1: (1-10), and can also be used for periodic watering of plants. The test was carried out at the Republican Unitary Enterprise "Institute of Vegetable Production" of the National Academy of Belarus. For testing used varieties: tomato Vezha, cucumber Zarnitsa, sweet pepper Parnassus. For growing plants used unheated film greenhouses. Before planting

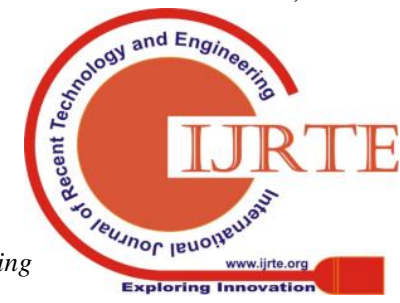


seedlings for crops, the general background of mineral fertilizers was introduced in doses: for tomato and sweet pepper: N75P120K150; for cucumber: N90P130K150. Mineral fertilizers were scattered in the form of ammonium nitrate, ammoniated superphosphate and potassium chloride in the spring under cultivation. When using the composition in comparison with the known one, the following are provided: in tomato plants - an increase in plant height by $8.7 \%$, stem diameter by $11.9 \%$, yield by $15.2 \%$, sugar content by $0.8 \%$, vitamin $\mathrm{C}$ by $2 \mathrm{mg} \%$, reduction in nitrate content by $7.7 \%$; in cucumber plants - an increase in the number of leaves by $10.1 \%$, leaf area by $10 \%$, plant height by $10.1 \%$, stem diameter by $16.3 \%$, yield by $12.8 \%$, sugar content by $0.3 \%$, vitamin C by $0.4 \mathrm{mg} \%$, a decrease in nitrate content by $32 \%$; in sweet pepper plants - an increase in plant height by $12 \%$, leaf number by $13.9 \%$, leaf area by $13.8 \%$, stem diameter by $13 \%$, yield by $16.1 \%$, sugar content by $1.1 \%$, vitamin $\mathrm{C}$ by $8.6 \mathrm{mg} \%$, reduction in nitrate content.

A number of patented technical solutions are devoted to the formation of artificial soils, which are proposed to be used for growing crops, as well as in the reclamation or enrichment of poor agricultural arable land, that is, in fact, for the expansion of agricultural land suitable for efficient farming. For example, CJSC Dormashinvest and Kochetov A.S. to increase the effectiveness of artificial soil, to use a nutrient medium of plant origin, and as a biologically active substance, non-toxic environmentally friendly carbon black of wood origin with a content of the latter by volume of 20-40\% (Kochetov et al. 27.06.2007). In another invention of the same patent holders (Kochetov et al. 06/20/2007), the soil contains peat as a moisture-absorbing material, and non-toxic carbon black of wood origin as a biologically active substance, their volume ratio is $40-60 \%$. The research-and-development enterprise APT-Ecology also received a patent (Kabirov et al. 04/10/1995) for an invention for a variant of artificial soil containing zeolite as a water-absorbing material, plant extract, nitrogen-fixing component and sapropel as a biologically active substance. The invention proposes to additionally include a gel-forming water-soluble non-toxic polymer as a water-absorbing material, and "Nostoc linckia", a blue-green alga, as a nitrogen-fixing component.

An interesting invention is the Oryol State Agrarian University (Stepanova et al. 02.27.2007) according to which in order to increase the yield of cultivated crops, spring screenings of aluminum slag are added to the soil for cultivation. The inventors have proved that this method intensifies both plant growth (potato yield increased by $31.7 \%$ ) and potato tuberization, and also increases the resistance of potato plants to late blight infection. Scientists of the Oryol State Agrarian University have also proved the effectiveness of the implementation of this method in research on peas, corn, potatoes and barley.

According to the invention of the All-Russian Research Institute of Agricultural Use of Reclaimed Land (Filippova et al. 06/27/1999), when the soil is enriched by introducing a layer of a mesh screen from the sorbent onto the sole of the arable layer, using zeolite as the sorbent, after applying zeolite to the soil, the surface is mineralized layer of soil, introducing mineral fertilizers into it.
Michurinsky State Agrarian University has patented an invention (Blinnikova et al. 06/10/2014) on a method for enriching iodine in fruits and berries of plants intended for the prevention of iodine deficiency. According to this method, the operation of foliar treatment of plant leaves is carried out once and is carried out by spraying with an aqueous solution of potassium iodide at different periods of the day during the formation of fruits and berries in plants. This technology of work allows increasing the iodine content in apples, fruits, in berries of wild strawberry (Fragaria ananassa), in edible honeysuckle (Lonicera caerulea var. Edulis), in actinidia (Actinídia deliciósa), in common mountain ash (Sórbus aucuparium), (Arónia melanocárpa). The same university also patented an invention (Blinnikova at ol, 11.27.2014) on a method for enriching manganese in fruits and berries, characterized in that it involves performing a single foliar treatment of leaves of trees, shrubs and plants with an aqueous solution of sulfate during the period of mass loading of fruits and berries. Manganese by spraying them. This ensures the production of fruits and berries of actinidia colomicta enriched with manganese, chokeberry, edible honeysuckle, garden strawberry, common mountain ash, apple tree (Mālus), intended for the prevention of manganese deficiency.

Other inventions of this university are also known: (Blinnikova et al. 01/10/2015) on a method of enrichment for producing magnesium-enriched fruits and berries (garden strawberries, edible honeysuckle, actinidia, apple, rowan and chokeberry) for the prevention of magnesium deficiency, in which single foliar treatment of plant leaves by spraying: (Blinnikova et al. 11.27.2014), aimed at obtaining zinc-enriched fruits and berries by double foliar treatment of plants by blooming leaves.

Thus, the important directions of innovative developments and patents in the field of enrichment of agricultural lands and plants growing on them include solving the problem of providing the population of Russia and the world with regulatory requirements for micro and macro elements: iodine, selenium, magnesium, calcium, manganese, zinc, etc., as well as in vitamins by pre-sowing, root, and foliar enrichment of cereal, fruit-bearing and vegetable crops in open and in closed ground.

\section{CONCLUSION}

Russian and foreign scientists have proved that the development of innovative technologies for the enrichment of agricultural land and plants growing on them is an important factor in the production of high-quality agricultural food raw materials for food production, including the production of functional food products. This will allow not only increasing the consumption of agricultural food raw materials from each hectare of arable land, but also improving the quality of functional food products produced from it, increasing their competitiveness in the domestic and foreign markets and making an important contribution to improving the food security of the country.

The development of innovative technologies for the enrichment of arable land and the plants growing on them 
creates the necessary conditions for increasing the natural productivity of agricultural soils and increasing the yield of grain and leguminous crops.

However, despite serious scientific research, in Russia insufficient attention is paid to the development and implementation of innovative technologies for the enrichment of agricultural lands and plants growing on them. Such technologies make it possible to purposefully bring the necessary micro and macro elements to agricultural plants, while ensuring, in turn, a significant increase in the consumer quality of agricultural products.

Russian universities and research organizations actively participate in the patenting of such developments: Volgograd State Agrarian University, All-Russian Research Institute of Selection and Seed Production of Vegetable Crops, All-Russian Research Institute of Agricultural Use of Reclaimed Lands, All-Russian Research Institute of Physical Culture and Sports, Geological Institute of the SB RAS, Institute of General and Experimental Biology SB RAS, Kemerovo Technological Institute of Food Industry, Michurinsky State Agrarian University, Oryol State Agrarian University, Volga Research Institute, Tomsk State University, and others., production companies and individuals.

The analysis showed that one of the important directions of innovative developments and patents in the field of enrichment of agricultural lands and plants growing on them is the solution to the problem of providing the population of Russia and the world with regulatory requirements for micro and macro elements: iodine, selenium, magnesium, calcium, manganese, zinc, etc. ., as well as in vitamins by pre-sowing, root, and foliar enrichment of cereal, fruit-bearing and vegetable crops in open and in closed ground. All this, in turn, will help to provide the country's population with high-quality food products derived from enriched agricultural raw materials and increase its competitiveness in the domestic and foreign markets.

The studies were the basis for the formation of an updated knowledge base on technologies and physical effects for the enrichment of arable land and plants growing on them to analyze the status and development trends of technologies and equipment in the field of enrichment of agricultural lands and plants growing on them for the production of high-quality agricultural food raw materials and use for food, including the production of functional foods.

\section{ACKNOWLEDGEMENTS}

The project "Research and development of end-to-end technology of functional food manufacture for achieving food supply security for north territories of the Russia" is carried out with granting by Russian Federation represented by Ministry of Education and Science of the Russian Federation (project identifier - RFMEFI57717X0264, agreement No 14.577.21.0264, 26.09.2017).

\section{REFERENCES}

1. Shegelman, I.R., Vasiliev, A.S. \& Shchukin, P.O. (2018). Particularities of ensuring food security in the conditions of the north of Russia. Astra Salvensis. Volume 6. 941-949.

2. Shegelman, I.R., Shchukin, P.O. \& Vasilev, A.S. (2019). Analysis of the current situation related to the food security of indigenous population of

the Northern Russia. EurAsian Journal of BioSciences. Vol. 13. Issue 2. 663-672.

3. Lubimaya, Yu.A. (2014). The basic principles of mineral fertilizers enrichment with microelements. Scientific works of Odessa National Academy of Food Technologies, no 1. Volume 46. 97-100.

4. Amagova, Z.A. \& Golubkina, N.A. (2018). Efficiency of using sodium selenate in growing tomato under oxidative stress. Ovoschi Rossiyi, no 1(39). 79-81

5. Azarov, V.B. (2004). Agroecological monitoring of agricultural lands of the South-Western part of the Central Black Earth Reserve. Belgorod.

6. Hong Chun-Lai, Weng Huan-Xin, Qin Ya-Chao, Yan Ai-Lan \& Xie Ling-Li (2008). Transfer of iodine from soil in vegetables is applying exogenous iodine. Ahron Sustain Dev, no 28(4). 575-583.

7. White, P.J. \& Broadley, M.R. (2009). Biofortification of crops with seven mineral elements often lacking in human diets: iron, zinc, copper, calcium, magnesium, selenium and iodine. New Phytol, no 182. 49-84.

8. Begeulov, M.Sh. \& Loshakov, V.G. (2015). Grain quality in specialized grain crop rotation with crop sideration. Reports of the Timiryazev Agricultural Academy. Volume 1. No 287-1. 15-19.

9. Gaplaev, M.Sh. \& Tsabolov, P.H. (2011). Sideration and mulching of the soil increase the yield and quality of carrots. Kartofel i ovoschi, no 5. 11

10. D’yachenko, E.N., Razina, A.A., Shevelev, A.T. \& Dyatlova, O.G. (2018) Technology for the integrated use of fertilizers, chemical and biological ameliorants, plant protection products in the fruit crop rotation. Zemledeliye, no 3. 28-31.

11. Khalmanov, N.T. (2017). The influence of sideration on chemical properties of sierozem soils of the Zarafshan valley in the republic of Uzbekistan. Pyt' nauki, no 2(36). 46-48.

12. Kashin, V.K. (1987). Biogeochemistry, phytophysiology and agrochemistry of iodine. Leningrad: Nauka.

13. Kashin, V.K. (2008). Iodine in the environment of Transbaikalia and the efficiency of plant enrichment with it. Khimiya v interesakh ustoychivogo razvitiya, no 2. Volume 16. 173-182.

14. Vorob'eva, T.N. (2018). Enrichment of the soil of vineyards with biomaterial that increases soil suppressivity and biotransformation of toxic inclusions. Scientific works of the North Caucasus Federal Scientific Center for Horticulture, Viticulture, Winemaking. Volume 18. 20-23.

15. Krasilnikov, A.A., Russo, D.E. \& Prah, A.V. (2018). The influence of the systemic application of foliar grape feeding on the quality of wine material and wine. Scientific works of the North Caucasus Federa Scientific Center for Horticulture, Viticulture, Winemaking. Volume 18. 49-55.

16. Golubkina, N.A., Kekina, E.G. \& Nadezhkin, S.M. (2015). Prospects for the enrichment of agricultural plants with iodine and selenium (review). Mikroelementy v meditsine, no 3. Volume 16. 12-19.

17. Melnichenko, G.A., Troshina, E.A., Platonova, N.M., Savchuk, P.O. \& Yakunchikova, M.S. (2016). Awareness of the Russian population about iodine deficiency diseases and methods for their prevention. Klinicheskaya i eksperimental'naya tireoidologiya, no 3. Volume 12. 23-50.

18. Karataeva, M.V., Selivanova, A.V., Chervyakovsky, K.I. (2015) Iodine-enriched vegetables and potatoes. Kartofel i ovoschi, no 1. 16-17.

19. Ermakov, V.V. \& Kovalskiy,V.V. (1974). The biological significance of selenium. Moscow: Nauka.

20. Sindireva, A.V., Fedosova, M.D. \& Knyazev, S.U. (2017). The effect of various concentrations of cadmium on the abundance, productivity of earthworms and phytotoxicity of the soil. Omsk. 410-416.

21. Golovatyi, S.E., Kovalevich, Z.S. \& Lukashenko, N.K. (2013). Parameters and forecast for the accumulation of selenium in the hay of perennial grasses when applying selenium fertilizer to the soil. Viesci Nacyjanaĺnaj akademii navuk Bielarusi. Sieryja ahrarnych navuk, no 1. 58-64.

22. Golubkina, N.A., Folmanis. G.E., Tananaev, I.G. et al. (2017) Comparative evaluation of spinach enrichment with selenium nanoparticles and ionic trace elements. Rossiyskiye nanotekhnologii, no 9-10. Volume 12. 105-112.

23. Endovitskiy, A.A., Esipenko, S.V. \& Hurum, H.D. (2012). Germination of seedlings of rice seeds when enriched with vanadium. Nauchnoye obespecheniye agropromyshlennogo kompleksa. 76-78.

24. Bardak, N.I. \& Petrik, Ya.B. (2017). Effect of copper enrichment on rice yield. Political Internet electronic scientific journal of the Kuban State Agrarian University, no 132. 288-305

25. Yakovleva, E.A., Bondareva, T.N. \& Sheujen, A.Kh. (2015). Productivity and quality of rice grain using iodine and boron fertilizers. Sovremennaya nauka: aktual'nyye problemy i puti ikh resheniya, no 1(14). 45-48. 
26. Sokolova, M.G., Akimova, G.P., Boyko, A.V., Nechaeva, L.V., Glyanko, A.K., Vayshlya, O.B. \& Vedernikova, A.A. (2008). The effect of bacterial biological products on potato harvest and its quality. Agrokhimiya, no 6. 62-67.

27. Blinnikova, O.M. \& Eliseeva, L.G. (2017). Enrichment of berries with magnesium and prospects for their use in preventive nutrition. Byulleten' nauki i praktiki, no 8(21). 70-78.

28. Weng, Y.X., Hong, C.L., Xia, T.H., Bao, L.T., Liu, H.P. \& Ki, D.W. (2013). Iodine biofortification of vegetable plants - an innovative method for iodine supplementation. Chinese Science Bulletin, no 17. 2066-2072.

29. Pyndak, V.I., Litvinov, V.I., Novikov, A.E. \& Megevova, A.S. (10.27.2016). Patent of the Russian Federation No. 2601217 "Fertilizer-reclamant."

30. Pyndak V.I., Novikov, A.E. \& Mezhevova, A.S. (10.27.2014). Patent of the Russian Federation No. 2532056 "Method for preparing a steam field."

31. Tsanirato, V. (27.02.2013). Patent of the Russian Federation No. 2476063 "Method and composition for enriching potatoes with iodine and potatoes obtained in this way."

32. Klimenko, V.I. (27.12.2001). Patent of the Russian Federation No. 2177226 "A method of protecting plants from diseases, regulating their growth and a protective-stimulating complex for its implementation."

33. Avtsin, A.G., Zhavoronkova, A.A. Rish, M.A. \& Strochkova, L.S. (1991). Trace elements of a person. Moscow: Meditsina.

34. Zubenko, V.F., Makovetskiy, K.A., Ustimenko-Bakumovskiy, A.V. et al. (1989). Improving the technological qualities of sugar beets. Kiev: Urozhai.

35. Minakova, O.A. (2011). Agroecological aspects of the use of fertilizers in grain-crop rotation of the forest-steppe Central Black Earth Economic Region. Voronezh.

36. Aliev, T.G.-G., Bobrovich, L.V., Usova, G.S., Matsnev, I.N. \& Palchikov, E.V. (2019). Promising soil maintenance systems in intensive pome crops. Tekhnologii pishchevoi i pererabatyvayushchey promyshlennosti APK produkty zdorovogo pitaniya, no 2. 29-33.

37. Golovatskaya, I.F., Karnachuk, R.A., Kulagina, Yu.M., Pavlova, D.G. \& Laptev, N.I. (27.05.2012). Patent of the Russian Federation No2451442 "A method for enriching selenium with vegetables and cereals."

38. Revensky, V. A. Zonkhoeva, E. L., Andreeva, D. B., Chimitdorzhieva, G. D., Tsybenov, Yu. B., Korsunova, C. D. \& Sanzhanova, S. S. (20.09.2006). Patent of the Russian Federation No. 2283821 "Method for the production of complex prolonged selenium-zeolite mineral fertilizer."

39. Revensky, V. A., Zonkhoeva, E. L., Andreeva, D. B., Chimitdorzhieva, G. D., Tsybenov, Yu. B., Korsunova, Ts. D.-Ts. \& Sanzhanova, S. S. (10.12.2008). Patent of the Russian Federation No. 2340152 "Method for producing a complex selenium-zeolite mineral fertilizer prolonged action".

40. Tikhonov, S.L., Tikhonova, N.V. \& Priymak, A.O. (16.07.2019). Patent of the Russian Federation No. 2694634 "Method for the enrichment of amaranth seeds with selenium."

41. Koroleva, T.A. \& Belitskaya, M.N. (20.12.2000). Patent of the Russian Federation No. 2160521"The method of presowing treatment of seeds."

42. Melikhov, V.V., Astakhov, A.A., Lomtev, A.V., Maslov, A.V., Saldaev \& A.M., Kudinov, Yu.R. (2004.11.2000). Patent of the Russian Federation No. 2239968 "Method for presowing treatment of seeds of vegetable crops."

43. Nesmeyanov, N.A., Nesmeyanov, A.N. \& Nesmeyanov, A.A. (20.03.2010). Patent of the Russian Federation No. 2384046 "A method for providing the root system of agricultural plants with biologically active water."

44. Golubenko, M.I. (04.06.2019). Patent of the Russian Federation No 2690656 "A method of enriching soil wi-th water using superabsorbent and using drainage livestock stocks on sod-podzolic sandy loamy soils of the Central Non-Black Earth Region."

45. Khodasevich, V.V., Khodasevich, V.V., Khodasevich, I.V. \& Podsobey, G.Z. (10.04.2015). Patent of the Russian Federation No. 2547132 "Composition for feeding plants."

46. Kochetov, A.S., Kovylin, V.M. \& Rezchikov, V.A. (20.06.2007). Patent of the Russian Federation No. 2301249 "Artificial soil."

47. Kochetov, A.S., Kovylin, V.M. \& Rezchikov, V.A. (27.06.2007). Patent of the Russian Federation No. 2301825 "Artificial soil."

48. Kabirov, R.R., Sadykov, O.F. \& Popkov, A.U. (10.04.1995). Patent of the Russian Federation No. 2032319 "Artificial soil."

49. Stepanova, L.P., Polovitskov, V.A., Tikhoykina, I.M. \& Cherny, E.S. (02.27.2007). Patent of the Russian Federation No. 2294076 "Method of soil enrichment in the cultivation of crops and ornamental plants."

50. Filippova, T.E. \& Kuzmin, E.A. (27.06.1999) Patent of the Russian Federation No. 2132122 "Method for soil enrichment using a layer of sorbent".
51. Blinnikova, O.M. \& Eliseeva, L.G. (10.06.2014). Patent of the Russian Federation No. 2519231 "Method for the enrichment of fruits and berries with iodine."

52. Blinnikova, O.M. \& Eliseeva, L.G. (10.01.2015). Patent of the Russian Federation No. 2537906 "Method for enrichment of fruits and berries with magnesium."

53. Blinnikova, O.M., Eliseeva, L.G. \& Novikova, I.M. (27.11.2014). Patent of the Russian Federation No 2534302 "A method of enriching zinc in fruits and berries."

54. Azim, R., \& Ghodrati Amiri, G. (2016). The Effects of Near and Far Fault Accelerograms Modification on Seismic Behavior of Concentrated Braced Steel Frames. UCT Journal of Research in Science, Engineering and Technology, 4(1), 16-25.

55. Alwahdani, A. (2019). The Impact of Trust and Reciprocity on Knowledge Exchange: A Case Study in IT Outsourcing. Journal of Information Systems Engineering \& Management, 4(1), em0084. 